Please do not remove this page

RMIT

UNIVERSITY

\title{
Reversal and pinning of Curie point transformations in thin film piezoelectrics
}

Bhaskaran, Madhu; Sriram, Sharath; Adley, David; Perova, Tatiana; Mitchell, Arnan

https://researchrepository.rmit.edu.au/esploro/outputs/9921857744401341/filesAndLinks?institution=61RMIT_INST\&index=null

Bhaskaran, M., Sriram, S., Adley, D., Perova, T., \& Mitchell, A. (2011). Reversal and pinning of Curie point transformations in thin film piezoelectrics. CrystEngComm, 13(5), 1280-1282.

https://doi.org/10.1039/c0ce00713g

Document Version: Accepted Manuscript

Published Version: https://doi.org/10.1039/c0ce00713g

Repository homepage: https://researchrepository.rmit.edu.au

(c) The Royal Society of Chemistry 2011

Downloaded On 2023/04/27 00:58:19 +1000

Please do not remove this page 
Thank you for downloading this document from the RMIT Research Repository.

The RMIT Research Repository is an open access database showcasing the research outputs of RMIT University researchers.

RMIT Research Repository: http://researchbank.rmit.edu.au/

\section{Citation:}

Sriram, S, Bhaskaran, M, Adley, D, Perova, T and Mitchell, A 2011, 'Reversal and pinning of Curie point transformations in thin film piezoelectrics', CrystEngComm, vol. 13, no. 5, pp. 1280-1282.

See this record in the RMIT Research Repository at:

http://researchbank.rmit.edu.au/view/rmit:10084

Version: Accepted Manuscript

Copyright Statement: (C) The Royal Society of Chemistry 2011

Link to Published Version:

http://dx.doi.org/10.1039/c0ce00713g 


\title{
Reversal and pinning of Curie point transformations in thin film piezoelectrics $\dagger$
}

\author{
Madhu Bhaskaran, ${ }^{* a}$ Sharath Sriram, ${ }^{a}$ David Adley, ${ }^{b}$ Tatiana S. Perova, ${ }^{b}$ and Arnan Mitchell ${ }^{a}$ \\ Received (in $X X X, X X X)$ Xth $X X X X X X X X X 2010$, Accepted $X$ th $X X X X X X X X X 2010$ \\ ${ }_{5}$ First published on the web Xth $X X X X X X X X X 2010$ \\ DOI: $10.1039 / b 000000 x$
}

The Curie point for a rhombohedral piezoelectric thin film was established by in situ micro-Raman spectroscopy. The hysteresis in phase reversal and specific thermal conditions for disrupting 10 such reversal were determined.

Piezoelectric materials are suitable for a wide range of applications such as transducers, actuators, and sensors. The operating temperature range of the piezoelectric materials for these applications is determined by the Curie point. ${ }^{1}$ The ${ }_{15}$ Curie point is the temperature above which the unit cell of piezoelectric compounds transforms from asymmetric tetragonal or rhombohedral arrangement to symmetric cubic arrangement; this renders them non-piezoelectric. ${ }^{1,2}$ The determination of the Curie point can be carried out using 20 electrical measurements of changes in the dielectric properties of materials. Kalinin and co-workers have reported on electric field induced first-order transformations in oxide thin films. ${ }^{3}$ However, techniques that can determine temperature dependent changes in crystal structure shed more scientific 25 insight into transformations, and also enable accurate evaluation of the Curie point of materials and hysteresis in recovery of the asymmetric piezoelectric crystal states.

Probing crystal structure transformations by micro-Raman spectroscopy has been shown to be suitable for the 30 determination of the Curie point for ceramics. ${ }^{4}$ Preliminary work by the authors, ${ }^{5}$ reported on the first determination of phase transformation temperatures for thin films using in situ measurements. The determination of Curie point proved to be challenging due to weak Raman signatures and limited 35 published literature. This indicated the need for further studies to improve understanding of Raman peak assignments for complex perovskite oxides such as the strongly piezoelectric $\mathrm{ABO}_{3}$-type lead zirconate titanate (PZT).

PZT is the most popular piezoelectric material given its 40 large piezoelectric response and wide operating temperature range. ${ }^{1,6}$ The addition of strontium as an $A$-site has been shown to enhance the piezoelectric response, ${ }^{7}$ but is expected to decrease the Curie point of the resulting material composition. The Curie point for these thin films of Sr-doped 45 PZT (PSZT) with composition $\left(\mathrm{Pb}_{0.92} \mathrm{Sr}_{0.08}\right)\left(\mathrm{Zr}_{0.65} \mathrm{Ti}_{0.35}\right) \mathrm{O}_{3}$ is expected to be around $250-280{ }^{\circ} \mathrm{C} .^{2,5}$

The Curie point induced transformations are considered to be reversible with temperature. ${ }^{1,2}$ This work aimed to study the phase transformations in rhombohedral $c$-axis oriented 50 thin films with increase in temperature, determine the thin film Curie point, and to check the reversibility of the same with controlled or uncontrolled cooling of the thin films.
Piezoelectric, perovskite-structured PSZT thin films were deposited by RF magnetron sputtering onto platinized silicon 55 substrates (see ESI $\uparrow$ for details). These $700 \mathrm{~nm}$ thick films were preferentially $c$-axis oriented with rhombohedral structure, as verified by X-ray diffraction (XRD) and transmission electron microscopy (TEM). ${ }^{8}$ A micro-Raman spectrometer combined with a Linkam hot-stage was used 60 extensively for in situ measurements (see ESI $\uparrow$ for details).

In order to determine the Curie point, PSZT thin film samples were heated with a controlled ramp rate of $10{ }^{\circ} \mathrm{C} / \mathrm{min}$. Heating was carried out to a maximum of $350^{\circ} \mathrm{C}$, based on the estimate of the Curie point being $\sim 280^{\circ} \mathrm{C} .{ }^{2,5}$ The sample was 65 held at maximum temperature for 20 minutes. The sample was then cooled with controlled ramp-down $\left(10^{\circ} \mathrm{C} / \mathrm{min}\right)$ until $100{ }^{\circ} \mathrm{C}$, beyond which the cooling occurred more gradually towards room temperature. Micro-Raman measurements were collected at selected set points, during the heating and cooling 70 cycle and twice at maximum temperature, during which the temperature was held constant for 8 minutes for this purpose.

PSZT thin films of this composition (with zirconiumtitanium ratio of 65/35) are in the rhombohedral phase at room temperature. Room temperature spectra highlight two main 75 Raman bands at $\sim 575$ and $\sim 744 \mathrm{~cm}^{-1}$ (see ESI†े, Fig. S1). These two bands have been reported in Raman investigations of PZT powders and thin films. ${ }^{9}$ On heating the PSZT thin films, these bands decrease in intensity, which can be attributed to increased scattering. These two bands are 80 asymmetric, with a few pronounced sub-peaks visible at room temperature. To isolate the constituent peaks, these bands

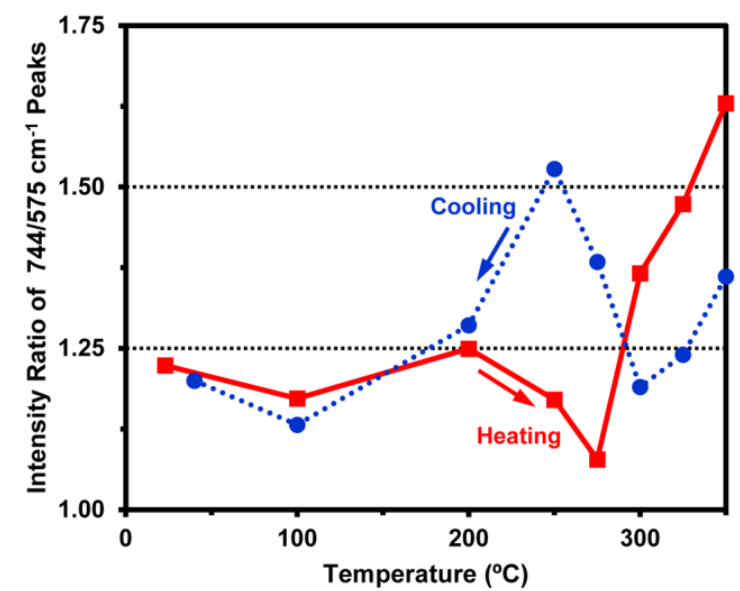

Fig. 1 Variation in the ratio of the intensities of the 744 and $575 \mathrm{~cm}^{-1}$ peaks with temperature during controlled heating and controlled cooling of the PSZT sample. 
(a)

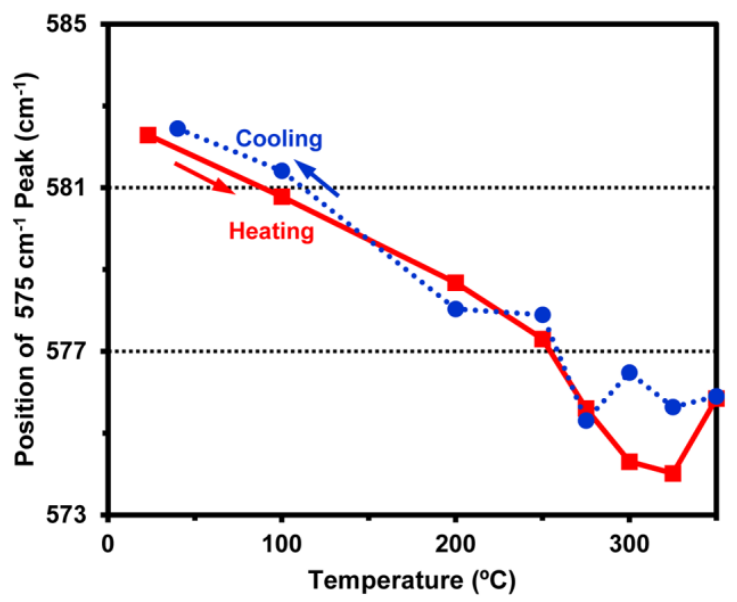

(b)

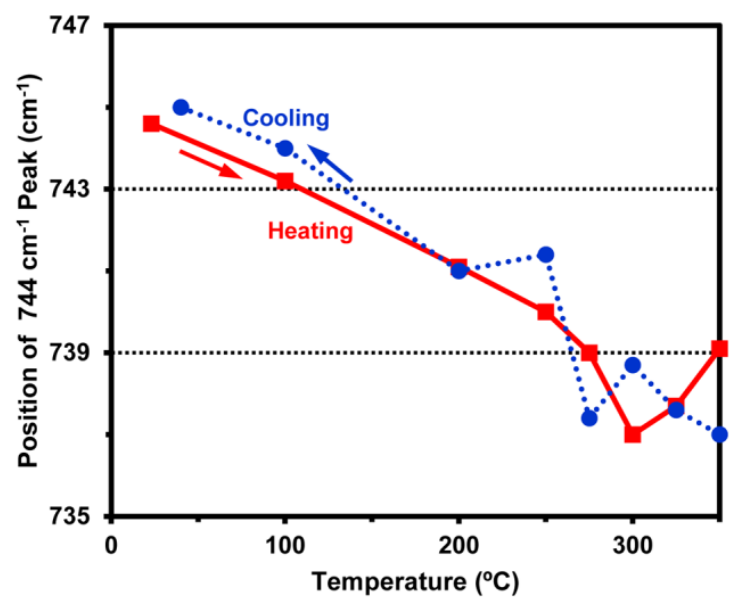

Fig. 2 Variation in the position of the (a) 575 and (b) $744 \mathrm{~cm}^{-1}$ peaks during controlled heating and controlled cooling of the PSZT sample.

were fitted with a collection of Gaussian/Lorentzian peaks. The band at $\sim 575 \mathrm{~cm}^{-1}$ was fitted with three sub-bands located at 565,575 , and $604 \mathrm{~cm}^{-1}$. The broad band centred at $\sim 744 \mathrm{~cm}^{-1}$ was also fitted with three sub-bands positioned at 5 725, 744, and $766 \mathrm{~cm}^{-1}$. In addition a small shoulder is observed at $\sim 815 \mathrm{~cm}^{-1}$. The position of some of these peaks is quite close to that obtained after the deconvolution of the two wide bands observed in the region from $450-620 \mathrm{~cm}^{-1}$ and $620-900 \mathrm{~cm}^{-1}$ for poled polycrystalline composites based on

${ }_{10} \mathrm{PZT}^{10}{ }^{10}$ It should be noted that our deconvolution produced three peaks for the $\sim 744 \mathrm{~cm}^{-1}$ band, with only two previously reported. This can be attributed to the more pronounced subbands in our spectra as a result of the preferentially textured polycrystalline crystallography of PSZT thin films grown 15 under optimised conditions; whereas, the sub-bands in published literature ${ }^{10,11}$ were not as pronounced. The stronger spectral contribution from the preferentially oriented PSZT, verified by XRD and TEM results, ${ }^{8}$ can also be confirmed from the results obtained by Foster et al., ${ }^{12}$ where the Raman 20 spectra of the oblique phonons of single-domain single crystal $\mathrm{PbTiO}_{3}$ were demonstrated. These results show that a large number of different phonon modes can be observed at room temperature $(300 \mathrm{~K})$ in the region from $420-800 \mathrm{~cm}^{-1}$ in platelet geometry for various directions of the phonon wave 25 vector $\boldsymbol{k}$ for the $\mathrm{PbTiO}_{3}$ crystal.

Having established the constituent peaks in the spectra, we now analyse the temperature dependence of different phonon modes obtained after fitting of the two wide bands described above. A comparison of the intensity ratios of the two peaks 30 provides accurate evidence of phase transformations. As can be observed in Fig. 1, the intensity ratio of the 744 and $575 \mathrm{~cm}^{-1}$ peaks increases at higher temperatures, following an apparent change at $275^{\circ} \mathrm{C}$. The sharp intensity ratio variations signify phase transformation, starting at the 35 theoretically expected value of $\sim 280^{\circ} \mathrm{C}$.

This phase transition observed can be related to the crystal structure of the thin film. The $575 \mathrm{~cm}^{-1}$ peak corresponds to the rhombohedral phase with a phonon assignment of A1(3TO). ${ }^{9,12}$ The $744 \mathrm{~cm}^{-1}$ peak is a combination of the 40 rhombohedral A1(3TO) and cubic $\mathrm{E}(3 \mathrm{LO})$ phonon assignments. ${ }^{9,12}$ As a consequence of this, while both peaks should appear at room temperature (for rhombohedral structure), on heating the $\mathrm{E}(3 \mathrm{LO})$ should dominate. ${ }^{12}$ This should result is an increased intensity ratio of the 45 744 and $575 \mathrm{~cm}^{-1}$ peaks, as seen in Fig. 1 .

With controlled cooling at $10^{\circ} \mathrm{C} / \mathrm{min}$, the cubic phase reverses back to the rhombohedral phase in the same temperature window of $275-300{ }^{\circ} \mathrm{C}$, indicating minimal hysteresis in the Curie point phase transformation. This 50 reversal occurs with the peak intensity ratio returning to $\sim 1.2$.

In addition to the intensity ratios, the position changes with temperature for the two main peaks were also studied, as this highlights changes in bond lengths corresponding to crystal structure. These results for the $\sim 575$ and $\sim 744 \mathrm{~cm}^{-1}$ peaks are ${ }_{55}$ presented in Fig. 2. After accounting for shifts related to thermal expansion, clear features of phase transformation can be observed. For the $\sim 575 \mathrm{~cm}^{-1}$ peak in Fig. 2(a), the peak position gradually decreases from $582 \mathrm{~cm}^{-1}$ (at $23{ }^{\circ} \mathrm{C}$ ) on heating. A sharp change in the slope of the position variation 60 occurs beyond $250{ }^{\circ} \mathrm{C}$, corresponding to the intensity ration changes in Fig. 1. However, the peak position behaviour is not as sharp as the peak intensity shown in Fig. 1 due to the fact that normally the peak intensity is more sensitive to the local change in the structure. The $\sim 744 \mathrm{~cm}^{-1}$ peak showed similar ${ }_{65}$ behaviour during heating as seen in Fig. 2(b). On cooling, reversal in peak positions of both peaks was observed (Fig. 2), with a hysteresis behaviour present.

The Curie point phase reversal is a critical contributor to high temperature deposition of piezoelectric thin films. Post70 deposition cooling rate is known to greatly influence the final crystal structure of the piezoelectric materials, with slower cooling producing best results (at $\sim 5{ }^{\circ} \mathrm{C} / \mathrm{min}$ ). ${ }^{6,13}$ Some hypothesise, in a principally intuitive manner, that this is due temperature-driven crystallisation given the larger duration 75 available for crystallisation. ${ }^{6}$ This theory can be tested by rapid cooling of a known rhombohedral film. We carried out this investigation, using a fully characterised film, as discussed in the earlier sections of this work,. The temperature of the PSZT thin films was allowed to ramp up slowly to 80 enable phase transformations, following which the effect of uncontrolled cooling on these films was studied. 
(a)

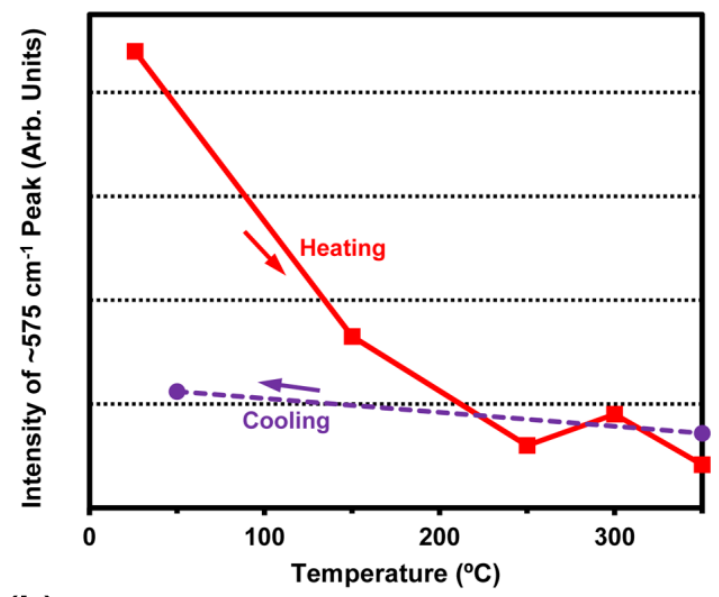

(b)

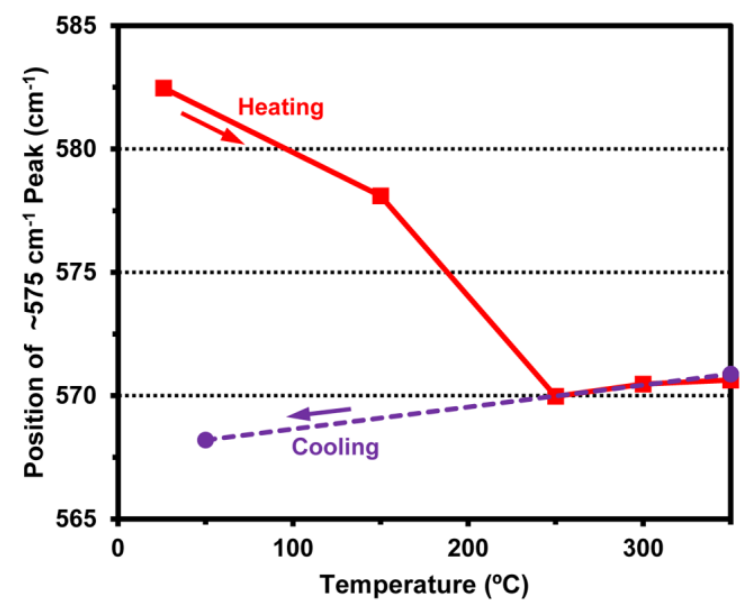

Fig. 3 Intensity and position variations of the $575 \mathrm{~cm}^{-1}$ peak during controlled heating and uncontrolled cooling are shown in (a) and (b), respectively.

The PSZT thin films produced spectra similar to the heating cycle (see ESI $\dagger$ ), carried out under identical conditions with a ramp rate of $10{ }^{\circ} \mathrm{C} / \mathrm{min}$. The expected Curie point transformation was observed beyond $275^{\circ} \mathrm{C}$. From the 5 maximum temperature of $350{ }^{\circ} \mathrm{C}$, the sample was cooled naturally. The behaviour of the 575 and $744 \mathrm{~cm}^{-1}$ PSZT micro-Raman peaks were studied in detail, with changes in intensity and position of the $575 \mathrm{~cm}^{-1}$ peak shown in Fig. 3 . The behaviour of composite peak areas is similar to that of the 10 earlier experiment during the controlled ramp-up of temperature. However, on rapid cooling of the sample, the peak intensities and positions remain locked in the cubic phase, indicating a permanent phase change has occurred (Fig. 3). Evidence of this pinning to the cubic phase is 15 provided by the observation of invariance in peak heights for the cooling measurements at $350{ }^{\circ} \mathrm{C}$ and $50{ }^{\circ} \mathrm{C}$, and by identical full range micro-Raman spectra (see ESI $\dagger$, Fig. S2). The absence of any relaxation to the room temperature rhombohedral phase was verified by a repeated measurement 20 of these samples after a period of four days and observing the same high temperature cubic phases at room temperature, indicating that this phase change is permanent. This result shows that actual cooling rate induced phase lock-in dominates any crystallisation process for these thin films.

25 In summary, we have carried out in situ heating with microRaman spectroscopy to study Curie point induced phase transformation in piezoelectric PSZT thin films. We have identified that Curie point transformation for these room temperature rhombohedral films occurs at $275^{\circ} \mathrm{C}$ and is a 30 reversible process with minimum hysteresis. The significance of the rate of cooling post deposition on reversal of Curie point transformations was studied. The results show that this can strongly disrupt Curie point transformations, by pinning the material to the high temperature cubic phase, if the ${ }_{35}$ cooling process is rapid and uncontrolled.

\section{Acknowledgements}

The authors acknowledge funding support from the Australian Research Council Discovery Project DP1092717 (MB); the ARC Australian Research Network for Advanced Materials 40 (MB); and the IRCSET, Ireland Postgraduate Award (DA).

\section{Notes and references}

${ }^{a}$ Microplatforms Research Group, School of Electrical and Computer Engineering, RMIT University, Melbourne, Victoria 3001, Australia. Email:madhu.bhaskaran@gmail.com

${ }_{45}{ }^{b}$ Microelectronics Technology Group, Department of Electronic and Electrical Engineering, University of Dublin - Trinity College, College Green, Dublin 2, Ireland.

$\dagger$ Electronic Supplementary Information (ESI) available: Experimental conditions for PSZT thin film deposition and for micro-Raman

50 spectroscopy measurements. Additional micro-Raman spectroscopy measurements results. See DOI: 10.1039/b000000x/

1 B. Jaffe, W. R. Cook and H. Jaffe, Piezoelectric Ceramics, Academic Press, New York, 1971.

2 H. Zheng, I. M. Reaney, W. E. Lee, N. Jones and H. Thomas, J. Am. Ceram. Soc., 2002, 85, 207.

3 S. V. Kalinin, S. Jesse, B. J. Rodriguez, Y. H. Chu, R. Ramesh, E. A. Eliseev and A. N. Morozovska, Phys. Rev. Lett., 2008, 100, 155703.

4 G. Burns and B. A. Scott, Phys. Rev. Lett., 1970, 25, 1191; W. J. Brya, Phys. Rev. Lett., 1971, 26, 1114; A . G. Souza Filho, K. S. V.

60 Lima, A. P. Ayala, I. Guedes, P. T. C. Freire, F. E. A. Melo, J. Mendes Filho, E. B. Araújo and J. A. Eiras, Phys. Rev. B, 2002, 66, 132107.

5 S. Sriram, M. Bhaskaran, T. S. Perova, V. A. Melnikov and A. S. Holland, IEEE Trans. Ultrason. Ferroelectr. Freq. Control, 2009, 56, 241.

6 K. Wasa, M. Kitabatake and H. Adachi, Thin Film Materials Technology: Sputtering of Compound Materials, Springer-Verlag GmbH \& Co. KG, Heidelberg, Germany, 2004.

7 S. Sriram, M. Bhaskaran, A. S. Holland, K. T. Short and B. A.

70 Latella, J. Appl. Phys., 2007, 101, 104910; S. Sriram, M. Bhaskaran and A. Mitchell, Scripta Materialia, 2010, 63, 189.

8 M. Bhaskaran, S. Sriram, D. R. G. Mitchell, K. T. Short and A. S. Holland, Thin Solid Films, 2008, 516, 8101.

9 C. E. F. Costa, F. M. Pontes, A. G. Souza, E. R. Leite, P. S. Pizani and E. Longo, Appl. Phys. A Mater. Sci. Process., 2004, 79, 593.

10 M. Deluca, T. Sakashita and G. Pezzotti, Appl. Phys. Lett., 2007, 90, 051919.

11 D. C. Agrawal, S. B. Majurnder, Y. N. Mohapatra, S. Sathaiah, H. D. Bist, R. S. Katiyar, E. Ching-Prado and A. Reynes, J. Raman Spectrosc., 1993, 24, 459.

12 C. M. Foster, Z. Li, M. Grimsditch, S.-K. Chan and D. J. Lam, Phys. Rev. B, 1993, 48, 10160.

13 S. Sriram, M. Bhaskaran and A. S. Holland, Semicond. Sci. Technol,, 2006, 21, 1236. 